\title{
Assessment of Diesel Particulate Matter Exposure of Underground Miners in Indonesia
}

\author{
Arif Susanto ${ }^{1.2}$, Purwanto Purwanto ${ }^{1,3}$, Henna R Sunoko ${ }^{1,4}$, Onny Setiani ${ }^{1,5}$ \\ 1 Doctorate Program in Environmental Science, School of Postgraduate Studies, University of Diponegoro, \\ Semarang 50241, Indonesia \\ 2 Department of Environmental Engineering, Faculty of Civil and Planning Engineering, University of \\ Kebangsaan Republic of Indonesia, Bandung 40263, Indonesia \\ ${ }^{3}$ Department of Chemical Engineering, Faculty of Engineering, University of Diponegoro, Semarang 50275, \\ Indonesia \\ ${ }^{4}$ Department of Medicine, Faculty of Medicine, University of Diponegoro, Semarang 50275, Indonesia \\ 5 Department of Environmental Health, Faculty of Public Health, University of Diponegoro, Semarang 50275, \\ Indonesia \\ *Corresponding author's e-mail: arifssnt@yahoo.com
}

\begin{abstract}
In Indonesia, there are underground mines for mineral metal such copper $(\mathrm{Cu})$ and gold $(\mathrm{Au})$, built by tunneling towards the mineral location. The purpose of this study was to determine the mapping a concentration of diesel particulate matter (DPM) and assess the impact on health by severity measurement of airflow obstruction of the miners experiencing chronic obstructive pulmonary disease (COPD). The data of DPM were measured with NIOSH method no. 5040 and applied a geostatistical method in mapping concentration at the area of underground mining. A spirometric measurement was conducted to diagnose COPD that is done to the 314 miners. The results showed that the concentrations exceeding the permissible exposure limit (PEL) and spirometric measurement were found for 26 miners $(8.3 \%)$ who experience COPD (post bronchodilator $<0.70$ ). The severity measurement of airflow obstruction of the miners experiencing COPD, severity of airflow limitation for moderate (GOLD 2) was obtained for 14 miners (54\%); severe (GOLD 3 ) for 10 miners (38\%) and very severe (GOLD 4) for 2 miners ( $8 \%$ ). It can be concluded that the amount of DPM exposure against the severity of airflow limitation with COPD by 0.03 , in which the other factors also affect the severity.
\end{abstract}

Keywords: airflow obstruction; COPD; DPM; geostatistics; PEL; spatial interpolation; severity measurement; underground miners.

\section{INTRODUCTION}

Diesel engines (DE) find use in industrial applications, including mining (off-road). Dieselpowered heavy equipment (HE) operating in underground (UG) environments (mines and tunnels) were determined by multiplying the vehicle power by a ventilation rate that was either mandated by regulation(s) or determined empirically from known quantities (Parent, 2007). The process of UG mining requires the application of (HE) such as loader as well as other types of equipment that use diesel engines (DE). Beside loader, haul truck, development jumbo, truck and other mine equipment with DE are found in the underground tunnels.
In Indonesia, Deep Ore Zone (DOZ) is an underground mine $(\mathrm{UG})$ for copper $(\mathrm{Cu})$ and gold (Au). The air pollutant concentration measurement in DOZ is the first step in identifying environmental-health hazards and risk to the miners. (Susanto et al., 2016; Susanto et al., 2017). Diesel fuel (DF) and DE are used increasingly frequently because of the reliability and efficiency of hydrocarbon fuel oxidation. However, there is a concern that the result of diesel engine oxidation is in the form of diesel engine exhaust (DEE) (USEPA, 2002; IPCS, 1996), which is dangerous for miners' health. This concern is related to the small size of respirable diesel particulate matter (DPM) (USEPA, 2002; Kittelson, 1998). 
The particles in DEE are DPM consisting of the center of carbon nucleus defined as elemental carbon (EC), and absorbed organic compounds defined as organic carbon (OC), as well as a small number of sulphate, nitrate, metal, and other elements (USEPA, 2002). DEE were classified as carcinogenic to humans (Group 1) (IARC, 2012), the decision was based on National Institute for Occupational Safety and Health (NIOSH) and US National Cancer Institute (NCI) study showed the exposure-response relationships between the respirable EC exposure and lung cancer mortality in UG miners (Attfield et al., 2012; Silverman et al., 2012). The highest levels of EC were reported for enclosed UG mining work sites (Rushton, 2012).

The exposure assessment is the process of measuring or estimating the magnitude, frequency and duration of human exposure to a compound in the environment (Susanto et al., 2016). The human exposure evaluation involved describing the nature and size of the population exposed to air contaminants as well as the magnitude and duration of their exposure. The dose, its duration and timing, the nature and size of the critical measures of exposure were taken into account for risk characterization (Birch et al., 1996; Birch et al., 2004).

DPM are usually less than one micron $\left(\times 10^{-6}\right.$ $m$ ) in size, which causes them to be more easily inhaled and retained in the body. Presently, the United States mining industry is in the process of phasing in stringent regulations relating to diesel particulates in underground mines. The exposure limits for DPM adopted by MSHA for metal or non-metal underground mines (non-coal). The present PEL for DPM as per MSHA (30 CFR $57.5060(\mathrm{~b})$ ) is $160 \mu \mathrm{g} \mathrm{TC} / \mathrm{m}^{3}$, defined as total carbon (TC) content (CDC, 2016).

Chronic obstructive pulmonary disease (COPD) is characterized by persistent respiratory symptoms and airflow limitation, usually caused by a significant exposure to noxious particles or gases. The burden of COPD is predicted to increase due to an additional exposure to environmental risk factors for the development of the disease and greater risk of the disease as the population ages (GOLD, 2017). Indonesia is a country with a high number of smokers, characterized by high COPD prevalence. Unfortunately, the COPD prevalence data are not owned by Indonesia; therefore, it is necessary to study COPD comprehensively so that its prevention can be done well. In 2017 , an updated and revised version of the standardsetting Global Initiative for Chronic Obstructive Lung Disease (GOLD) guidelines was released as depicted in table 1 (Classification of COPD based on GOLD 2017). As part of the revision, the definition of COPD was updated to include the importance of environmental disturbances and host factors that contribute to the disease pathophysiology.

The most prevalent environmental risk factor for COPD is cigarette smoking, which is associated with a higher mortality rate, a higher burden of respiratory symptoms and lung function abnormalities, as well as greater decreases in lung function. For the diagnosis of COPD in patients with risk factors, a spirometric assessment is conducted to confirm the presence of persistent airflow limitation. The patients with the severity of airflow limitation post bronchodilator of less than 0.70 forced expiratory volume in one second $\left(\mathrm{FEV}_{1}\right)$ / forced vital capacity (FVC) are considered to have a spirometrically confirmed diagnosis (GOLD, 2017).

\section{METHODS}

The research was carried out in DOZ, which is a production area of UG located on the coordinate points of $73^{\circ} 32^{\prime} 50^{\prime \prime}$ - $73^{\circ} 42^{\prime} 50^{\prime \prime}$ Easting; 95 $12^{\prime} 50^{\prime \prime}-95^{\circ} 22^{\prime} 50^{\prime \prime}$ Northing; UTM Zone 53 South. The mining site is situated in Jayawijaya Mountain, East Mimika District, Papua Province, Indonesia. The measurements representing the ambient conditions were taken and a comprehensive chemical analysis was performed. The data of DPM as TC was defined as the sum of EC and OC. Both EC and OC were measured by NIOSH method number 5040.

This study applied spatial analysis by universal kriging for mapping DPM concentration in the area truck haulage drift at DOZ. The data obtained from these calculations were then processed into a frame using a spatial model. It has been most frequently used for providing boundary conditions to the dynamic modeling of the air pollution. In the current study, ArcGIS were used for generating maps. Spirometric measurements were conducted to diagnose COPD and the assessment of airflow limitation based on GOLD, was conducted on the 314 miners that work at the DOZ (Table 1). 
Table 1. Classification of COPD based on GOLD

\begin{tabular}{|c|c|c|}
\hline & Stage & Spirometric Findings \\
\hline I. & Mild & $\begin{array}{ll}\text { - } & \text { FEV } 1 / F V C<0.70 \\
\text { - } & \text { FEV } 1 \geq 80 \% \text { predicted }\end{array}$ \\
\hline II. & Moderate & $\begin{array}{ll}\text { - } & \text { FEV } 1 / F V C<0.70 \\
\text { - } & 50 \%<\text { FEV } 1<80 \% \text { predicted }\end{array}$ \\
\hline III. & Severe & $\begin{array}{ll}\text {. } & \text { FEV } 1 / F V C<0.70 \\
\text { - } & 30 \% \leq \text { FEV } 1 \leq 50 \%\end{array}$ \\
\hline & Very Severe & $\begin{array}{ll}\text { - } & \text { FEV } 1 / F V C<0.70 \\
\text { FEV } 1 \leq 30 \% \text { predicted; or } \\
\text { FEV } 1 \leq 50 \% \text { predicted plus } \\
\text { chronic respiratory failure }\end{array}$ \\
\hline
\end{tabular}

\section{RESULTS AND DISCUSSION}

The DOZ mine airflow area providing sufficient airways were required based on the minimum velocity concern in main travelways and dilution of diesel contamination (Stinnette \& Souza, 2013). The total airflow demand is $1.498 \mathrm{~m}^{3} / \mathrm{s}$. Airflow to each primary level, undercut, extraction and haulage was based on providing 0.079 $\mathrm{m}^{3} / \mathrm{s} / \mathrm{kW}$ over diesel equipment and a minimum air velocity of $0.76 \mathrm{~m} / \mathrm{s}$ in the areas where personnel and non-diesel operate (Susanto et al., 2016). The intake and exhaust airways were required to provide sufficient airflow. It involves multiple parallel drifts on the extraction (production) level to control block-caving mines. Concerning the main trailways, the airflow is required for dilution of DEE contamination. The ventilation system was designed to provide fresh air for all personnel working in truck haulage drifts. Determination of airflow quantity is influenced by mining equipment and wide variations in the characteristics of emissions even amongst vehicles of similar size and power. A number of parameter affects the total airflow required for a given amount of DE.

\section{DEE SURVEY AND MEASUREMENT}

DEE is a complex mixture of DF combustion products (table 2 shows the quality analysis for diesel usage in DOZ), and the exact composition of the mixture depends on the nature of engine, operating conditions, lubricating oil, additives, emission control system, and fuel composition (Pronk et al., 2009). DPM generation varies considerably among types, sizes, series manufacturers of DE. DPM behave as an aerosol (Stinnete \& Souza, 2013). Being sub-micron in size, they have aerodynamic diameters falling within a range 0.1 to $0.25 \mu \mathrm{m}$; thus, their control is similar to other gaseous contaminants. The composition of DPM concentration was taken from the data analysis as depicted in table 3. Its peaks data without could provide information about the spatial changes in the composition of the organic and gas component.

Table 2. Diesel fuel quality analysis results

\begin{tabular}{|c|c|c|c|c|}
\hline Test & Method & Units & Limits & Result \\
\hline Appearance @20C & Visual & - & Clear \& bright & Clear \& bright \\
\hline Ash content & ASTM D482-13 & $\%$ mass & $\operatorname{Max} 0.01$ & $<0.001$ \\
\hline Water and sediment & ASTM D2709-96(11)e1 & $\%$ V/V & Max 0.05 & $<0.005$ \\
\hline Micro carbon residue $10 \%$ bottom & ASTM D4530-11 & $\%$ mass & $\operatorname{Max} 0.16$ & $<0.10$ \\
\hline Cetane index & ASTM D4737-10 & - & Min 47 & 47.5 \\
\hline Cloud Point & ASTM D2500-11 & ${ }^{\circ} \mathrm{C}$ & Max 0 & -3 \\
\hline Cold Filter Plugging Point & IP 309/99 & ${ }^{\circ} \mathrm{C}$ & Max -3 & -4 \\
\hline ASTM Color & ASTM D1500-12 & - & $\operatorname{Max} 2.5$ & L1.5 \\
\hline Copper Corrosion (3hrs @100C) & ASTM D130-12 & - & Max 1 & $1 \mathrm{~A}$ \\
\hline Density at $15^{\circ} \mathrm{C}$ & ASTM D4052-11 & $\mathrm{Kg} / \mathrm{L}$ & $0,820-0.870$ & 0.8597 \\
\hline Distillation Range & ASTM D86-12 & - & Report & - \\
\hline $50 \%$ recovered & ASTM D86-12 & ${ }^{\circ} \mathrm{C}$ & Report & 280.1 \\
\hline $90 \%$ recovered & ASTM D86-12 & ${ }^{\circ} \mathrm{C}$ & Max 357 & 332.8 \\
\hline Flash point & ASTM D93-13 (Proc A) & ${ }^{\circ} \mathrm{C}$ & Min 60 & 87.0 \\
\hline Lubricity - method HFRR & IP $450 / 00$ & $\mu \mathrm{m}$ & $\operatorname{Max} 460$ & 360 \\
\hline Total Acid Number & ASTM D974-12 & $\mathrm{MgKOH} / \mathrm{g}$ & Max 0.25 & 0.03 \\
\hline Strong Acid Number & ASTM D974-12 & $\mathrm{mgKOH} / \mathrm{g}$ & Nil & Nil \\
\hline Oxidation Stability & ASTM D2274-10 & $\mathrm{mg} / \mathrm{L}$ & Max 15 & 5 \\
\hline Sulphur & ASTM D2274-10 & $\%$ mass & Max 0.05 & 0.0284 \\
\hline Kinematic Viscosity at $40^{\circ} \mathrm{C}$ & ASTM D445-12 & $\mathrm{mm}^{2} / \mathrm{s}$ & $1.9-5.5$ & 3.270 \\
\hline
\end{tabular}


Table 3. Descriptive statistics of DOZ Truck Haulage for DPM

\begin{tabular}{|l|c|c|c|c|}
\hline \multicolumn{1}{|c|}{ Area } & $\mathrm{n}$ & Average & Min-Max & PEL \\
\hline Access Center Crusher \#1-2 & 2 & 42 & $0-84$ & 160 \\
\hline Truck Haulage Shop & 5 & 247.2 & $140-527$ & 160 \\
\hline Maintenance Shop & 2 & 164.5 & $154-175$ & 160 \\
\hline Office Area & 6 & 154.5 & $66-428$ & 160 \\
\hline PM Shop & 2 & 161 & $53-269$ & 160 \\
\hline Welding Shop & 3 & 172 & $90-272$ & 160 \\
\hline West Empty Haulage & 2 & 223.5 & $179-568$ & 160 \\
\hline South Full Haulage & 2 & 1151 & $1055-1247$ & 160 \\
\hline Access \#1HN to 1JS & 2 & 171 & $0-342$ & 160 \\
\hline Access South Empty & 2 & 591 & $0-1182$ & 160 \\
\hline Access West Full Haulage \#10 & 2 & 263.5 & $0-527$ & 160 \\
\hline Access West Full Haulage \#1-6 & 2 & 214 & $0-428$ & 160 \\
\hline Center Crusher \#1 & 2 & 204 & $175-233$ & 160 \\
\hline Center Crusher \#2 & 2 & 185.5 & $160-211$ & 160 \\
\hline LP\#1 E-1F South & 2 & 595.5 & $0-1191$ & 160 \\
\hline LP\#1 G South & 2 & 591.5 & $0-1183$ & 160 \\
\hline LP\#1 H South & 2 & 971.5 & $725-1218$ & 160 \\
\hline LP\#1 J South & 2 & 198.5 & $194-203$ & 160 \\
\hline LP\#1 IE & 2 & 798 & $759-837$ & 160 \\
\hline
\end{tabular}

In order to validate a determination of a miner's exposure based on a personal TC sample, MSHA will analyze a non-citable area sample taken from an area of the mine without organic carbon (OC) interferences. MSHA will multiply the elemental carbon (EC) component of the personal TC sample by the ratio of TC to EC obtained from the area sample to check for non-diesel OC interferences on the personal samples. MSHA uses this procedure when EC on the miner's personal sample is $<160 \mu \mathrm{g} / \mathrm{m}^{3}$ of air times the error factor $(\mathrm{EF})$ for $\mathrm{EC}$, and TC on the miner's personal sample is $>160 \mu \mathrm{g} / \mathrm{m}^{3}$ of air times the EF for TC. MSHA will obtain both personal and area samples using the same type of sampling cassette, previously employed for its compliance sampling. TC from a personal sample must $>160 \mu \mathrm{g} / \mathrm{m}^{3}$ times the $\mathrm{EF}$ for TC to result in a miner's overexposure to DPM. The EF for TC is 1.192. Thus, it follows that the miner is not excessively exposed to DPM when TC from the miner's personal sample is $\leq 160 \mu \mathrm{g} / \mathrm{m}^{3}$ times the EF for TC.

\section{GEOSTATISTICS - SPATIAL INTERPOLATION}

In order to obtain spatial interpolation analysis is using air dispersion model by numerically processing the emission and meteorological data (Zou et al., 2009). Kriging is a commonly used method and represents spatially continuous phenomena. The method has formed the basis for environmental pollution mapping in recent years (Isaaks et al., 2013). This method describes DOZ mine air quality exposure model for predicting DPM concentrations to which the miners are exposed.

Air pollution analysis and points of monitoring and measurement (truck haulage drifts and tunnels) used in this studies of various pollutants from HE operating in UG environments. Air polutant data measurements are used in assessment use of Geographic Information System (GIS) based Kriging method to produce the most accurate and useful information about the spatial interpolation patterns pertaining to DPM concentration in DOZ. Mapping was built in ArcGIS, integrating the relevant data on truck haulage drifts, tunnels and ventilation rate. The results that show DPM can be estimated, mapped and visualized within a GIS framework (Susanto et al., 2017). The spatial distribution of the pollutants is an integral component from risk evaluation aspect concerning health and environment. The technique used for illustrating the spatial distribution provides a meaning for estimating the probability of the attribute value, which exceeds the required threshold in a particular location (Cattle et al., 2002).

The results of the air pollutant concentration mapping was DPM with universal kriging (Figure 2), this method is also useful for identifying metallic (Fonturbel et al., 2011) and par- 


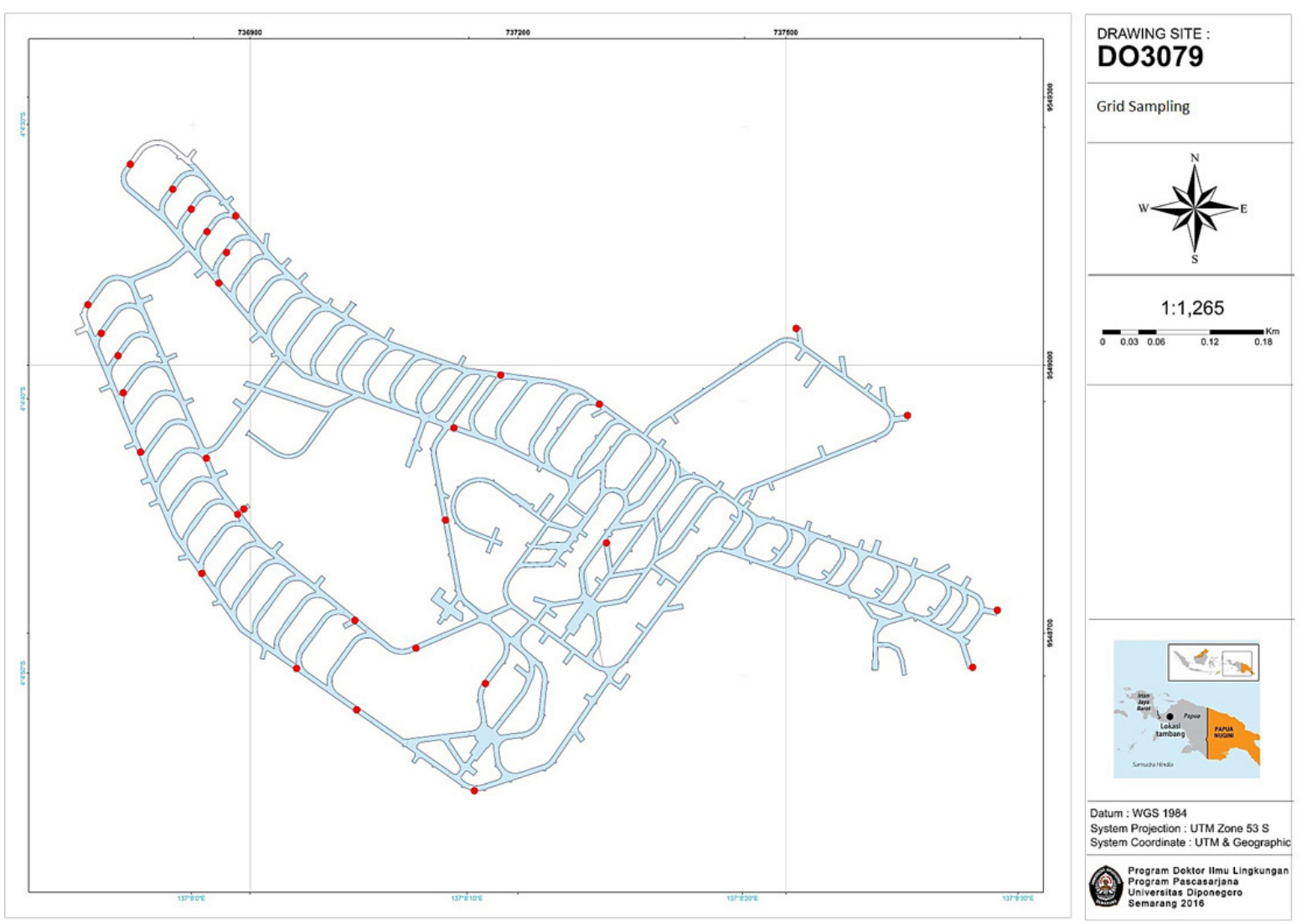

Figure 1. Grid sampling location at truck haulage area for DPM measurement

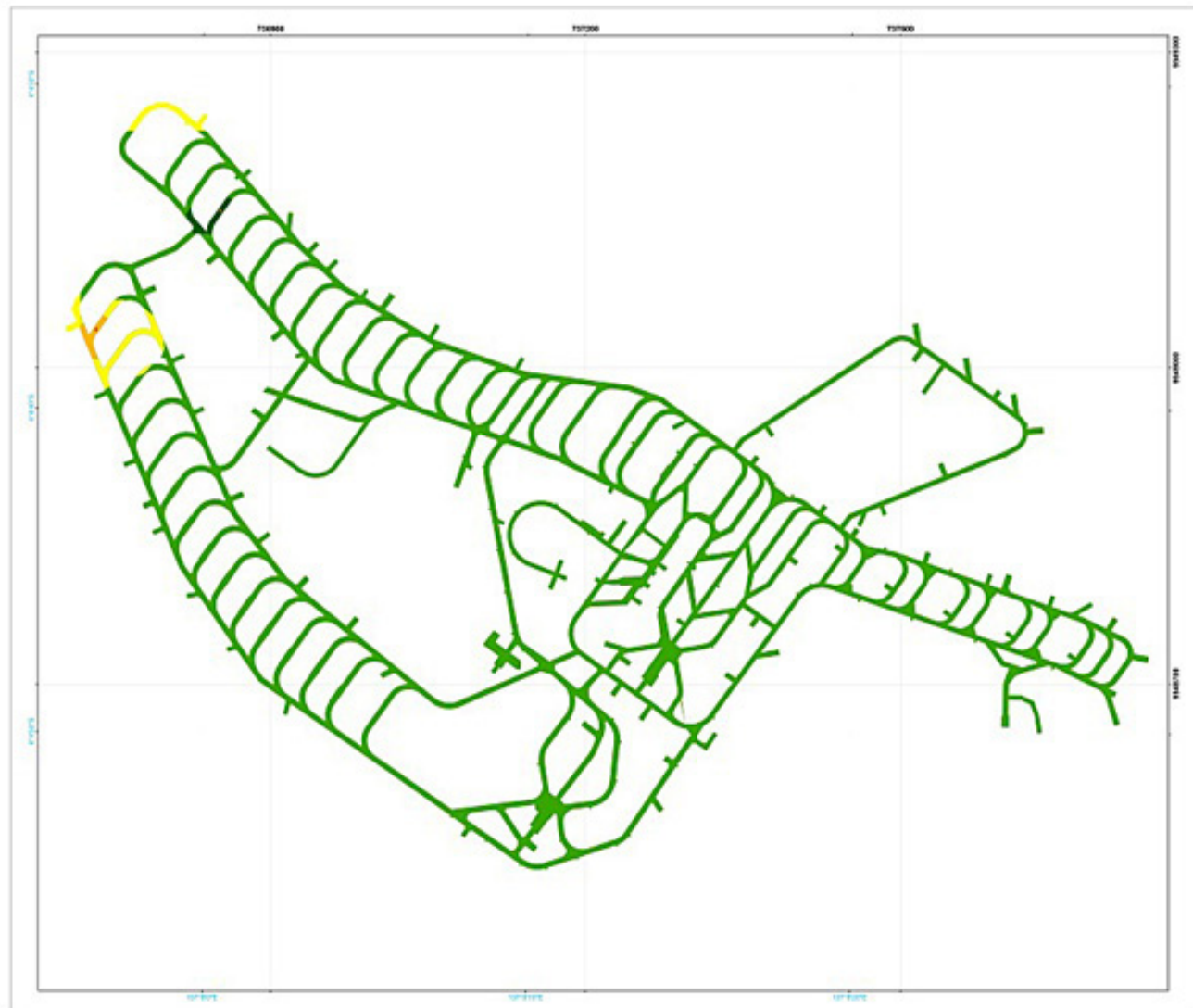

\section{DRAWING SITE}

DO3079

DPM

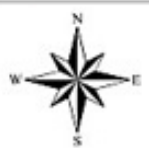

$1: 1,200$

$-1,-$

Remarks:

$68.27-343.25$

$343.26 \cdot 618.23$

$618.24-893.21$

$89322 \cdot 1168.18$

$1168.19 \cdot 1443.16$

.

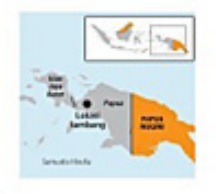

Dasum : Wos 1004

Systen Projection : UTM Zoce 538

Spetem Coersinatio: UTM \& Geograph

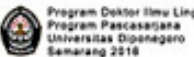

Figure 2. DPM pollutant map at the truck haulage area 
ticulate matter (Gulliver et al., 2011; Brauer et al., 2003). In general, it indicated a high concentration; therefore, denoting bad conditions at the truck haulage area, even though no difference in DPM concentration was found. Most areas had the DPM concentration ranging from 343.26 to $618.23 \mathrm{mg} / \mathrm{m}^{3}$. In some areas, the rates were 618.24 to $1168.18 \mathrm{mg} / \mathrm{m}^{3}$. Although the air quality inside the DOZ was affected by the balance of the total air intake and exhaust, as the part of ventilation system to supply the needs for air, the quality is still not capable of diluting air pollutants, in particular DPM. The air requirement for all mining workers was 650 individuals with operational factor of $100 \%$, where the total airflow per unit reached $0.03 \mathrm{~m}^{3} / \mathrm{s}$. Besides, the airflow quantity necessary for each unit type of the diesel equipment was characterized by the operational factor depending on the power unit (in horsepower unit), which was different from the unit type affected by operational factor of each unit equipment (Susanto et al., 2016). Figure 2 shows spatially continuous DPM concentrations mapping for points where there are no measurement data which have to be estimated by a spatial interpolation.

The measurement values of both minimum and maximum DPM concentrations were presented in table 3. Minimum airflow value of 0.03 $\mathrm{m}^{3} / \mathrm{s} /$ worker and $0.067 \mathrm{~m}^{3} / \mathrm{s} / \mathrm{kW}$ for DEE dilution as per Indonesian Mining Regulation (Susanto et al., 2016; Susanto et al., 2017). Actually, 0.080 $\mathrm{m}^{3} / \mathrm{s} / \mathrm{kW}$ is a design value and is higher than the typical MSHA equipment quantities provided for gaseous compliance (Matejicek, 2005). For truck haulage routes, the maximum velocity is $6.1 \mathrm{~m} / \mathrm{s}$. The ventilation for diesel shops based on the dilution of exhaust gaseous for two large loaders, requires approximately $40.0 \mathrm{~m}^{3} / \mathrm{s}$. The ventilation of non-diesel shops has been established at $23.5 \mathrm{~m}^{3} / \mathrm{s}$ based on the experience at the mine. The airflow through the lube shop areas has been determined to be $28.2 \mathrm{~m}^{3} / \mathrm{s}$, based on the expected equipment usage. The operating factors represent the percentage of time that the equipment will be running and have to be applied in order to determine approximate airflow requirements.

\section{CHRONIC OBSTRUCTIVE PULMONARY DISEASE (COPD)}

Environmental exposures to fumes, gases, air pollutants, and occupational dusts contribute to impaired lung function. The most prevalent environmental risk factor for COPD is cigarette smoking, which is associated with a higher mortality rate, a higher burden of respiratory symptoms and lung function abnormalities, and greater decreases in lung function. Spirometric measurement for COPD diagnosis was done to 314 miners that work at the DOZ.

Table 4 shows the frequency distribution of miner age with an average of 37.87 years of age. The age range indicates that the miners are in the productive age. In spirometric measurement other than gender (sex), age is a factor that must be considered (GOLD, 2017). This is in accordance with the 'age range under observation' contained in Figure 3 that is the graph of FEV ${ }_{1}$ progression over time.

The height ranges from 1.45 to $1.84 \mathrm{~m}$ with the mean of $1.64 \mathrm{~m}$ which is the range of average height for Indonesians. The miners usually work in DOZ for 15 years. This is in line with the mining age of DOZ which began operating in 1998. The years of working are in accordance with the amount of time of DEE exposure. The exposure to particles is a factor that affects disease progression, although it is also affected by age and sex, although in this study, gender is not used as an independent variable because all miners in $\mathrm{DOZ}$ are male. The prevalence of COPD was higher in smokers and ex-smokers Compared to non-smokers (GOLD, 2017). The number of non-smokers is 142 miners ( $45.2 \%$ of the total number of miners), which is less when compared with the miners who smoke, i.e. 172 miners $(54.8 \%$ of the total number of miners) $-9.8 \%$ higher than miners as non-smokers.

COPD is considered in a history of exposure to risk factors for the disease. Table 5 shows that the results of spirometry measurement, the presence of a post-bronchodilator $\mathrm{FEV}_{1} / \mathrm{FVC}<0.70$ confirms the presence of persistent airflow limita-

Table 4. Descriptive statistics of miners' demography

\begin{tabular}{|l|c|c|c|c|}
\hline \multicolumn{1}{|c|}{ Description } & N & Min-Max & Mean & 37.87 \\
\hline Age & 314 & $22.0-57.0$ & 1.64 & 0.611 \\
\hline Height & 314 & $1.45-1.84$ & 15.21 & 6.043 \\
\hline Working Years & 314 & $2.0-34.0$ & & 056 \\
\hline
\end{tabular}




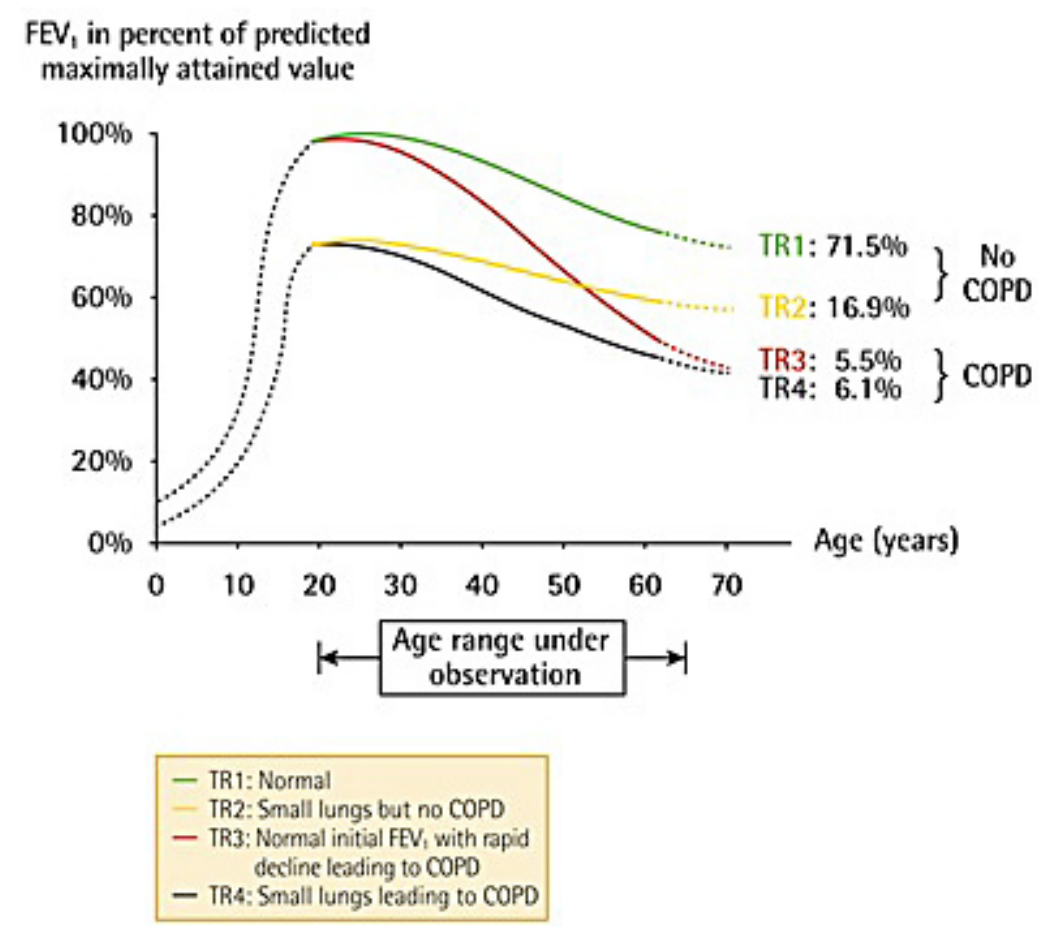

Figure 3. FEV1 progression over time

tion on as many as 26 out of 314 miners (8.3\%). Thus, it can be said that exposure to DEE can cause COPD on the miners who worked in DOZ.

\section{ASSESSMENT OF SEVERITY OF AIRFLOW OBSTRUCTION}

The 2017 GOLD guidelines introduce an updated ABCD assessment tool for COPD disease severity that requires the formal assessment of disease-specific symptoms and an evaluation of patient history of the exposure to the disease risk factors in order to determine the disease severity independently from the spirometric results (table 6). In order to measure the severity of airflow obstructive toward the miners who experience COPD, a follow-up test was conducted on miners with $\mathrm{FEV}_{1}$ (\% predicted), assessed on the miners with $\mathrm{FEV}_{1} / \mathrm{FVC}<0.70$; the obtained results of the severity of airflow limitation classification for the miners with COPD are: for moderate (GOLD 2) - 14 miners or $54 \%$, severe (GOLD 3 ) -10 miners or $38 \%$, and very severe (GOLD 4) -2 miners or $8 \%$, as described in Table 6 .

Following the assessment of airflow limitation mentioned above, ANOVA test was conducted by enter method to determine the amount of working time (exposure) DPM against severity of airflow limitation with COPD and whether other factors including age and smoking habits which can also affect the severity. The obtained results show that the value $\mathrm{R}=0.173$ with value $\mathrm{F}=2.395$ on the value of significance $(\alpha)=0.05$, so it can be concluded that the GOLD category is influenced by $3 \%$ of the length of exposure to DPM, height, smoking habits, and age of miners.

COPD is one of the non-communicable diseases, which is rarely exposed due to lack of information provided. In the United States. the data in 2007 shows that the COPD prevalence $10.1 \%$ (SD 4.8) for male is $11.8 \%$ (SD 7.9) and for women is $8.5 \%$ (SD 5.8) (Buist et al., 2007). Mortality ranks at the fourth position as highest factor that is 18.6 per 100,000 people in 1991 and the death rate increased as much as $32.9 \%$ from 1979 up to 1991 (AST, 1995). The COPD prevalence in Southeast Asian countries is estimated as much as $6.3 \%$ with the highest occurrence found in Vietnam (6.7\%) and China (6.5\%) (Yeung et al., 2004). COPD will negatively affect the quality of life, including $>40$ years that will lead to disability toward the patients. Though they are still in the productive age group, they cannot work optimally due to chronic breathlessness. The co-morbidity of COPD will result in cardiovascular disease, bronchial cancer, lung infections, embolic thrombosis disorder, the presence of asthma, hypertension, osteoporosis, joint pain, depression and axiety (Agusti et al, 2003). 
Table 5. Descriptive statistics of spirometric measurement results

\begin{tabular}{|c|c|c|c|c|}
\hline \multicolumn{2}{|c|}{ Description } & Frequency & Percent & Cumulative Percent \\
\hline \multirow{3}{*}{ Valid } & Not COPD & 288 & 91.7 & 91.7 \\
\cline { 2 - 5 } & COPD & 26 & 8.3 & 100 \\
\cline { 2 - 5 } & Total & 314 & 100 & \\
\hline
\end{tabular}

Table 6. Results of Severity Measurement of Airflow Limitation Assessment with COPD

\begin{tabular}{|c|c|c|c|c|}
\hline Severity of Airflow Limitation & Classification & $\mathrm{FEV}_{1}{ }^{a}$ & Frequency & Cumulative Percent \\
\hline Mild & GOLD 1 & $\geq 80 \%$ & 0 & 0 \\
\hline Moderate & GOLD 2 & $50-79 \%$ & 14 & 54 \\
\hline Severe & GOLD 3 & $30-49 \%$ & 10 & 38 \\
\hline Very Severe & GOLD 4 & $<30 \%$ & 2 & 8 \\
\hline
\end{tabular}

FEV1 indicates forced expiratory volume in 1 second; FVC forced vital capacity

${ }^{a}$ Assessed in the patients with FEV1/FVC less than 0.70

\section{CONCLUSIONS}

The survey results that have been conducted in DOZ show that the concentration of DPM ranges from 643.26 to $618.23 \mu \mathrm{g} / \mathrm{m}^{3}$. The results of spirometric measurements show that $8.3 \%$ miners experience COPD (post-bronchodilator $<0.70$ ). The severity measurement of airflow obstruction to miners experiencing COPD depends on the amount of working duration (exposure) DPM against severity of airflow limitation with COPD by $3 \%$; the other factors are age and smoking habits, which also affects the severity. From these results, it was concluded that the concentration mapping can be used to evaluate exposureresponse relationships. The estimated exposure of the DPM pollutant was recommended to perform as the part of the study on predicting whether the pollutant has any impact on health condition of the mining workers in a long-term exposure.

\section{REFERENCES}

1. Agusti, A.G.N., Noguera, A., Sauleda, J., Sala, E., Pons, J. and Busquet, X. 2003. Systemic effect of COPD. Eur Respir J, 21: 347-360.

2. Attfield, M.D., Schleiff, P.L., Lubin, J.H., Blair, A.E., Stewart, P.A., Vermeulen, R., Coble, J.B. and Silverman, D.T. 2012. The diesel exhaust in miner study: a cohort mortality study with emphasis on lung cancer. J Natl Cancer Inst, 104: 869-883.

3. ATS. 1995. Standards for diagnosis and care of patient with COPD. Am J Respir Crit Care Med, 152: S77-120.

4. Birch, M.E. and Cary, R. 1996. Elemental carbonbased method for occupational monitoring of par- ticulate diesel exhaust: methodology and exposure issues. Analyst, 121: 1183-1190.

5. Birch, M.E. and Noll, J.D. 2004. Submicrometer elemental carbon as selective measure of diesel particulate matter in coal mines. J Environ Monit, 6: 799-806.

6. Brauer, M., Hoek, G., Vliet, P.V., Meliefste, K., Fischer, P., Gehring, U., Heinrich, J., Cyrys, J., Bellander, T., Lewne, M. and Brunekreef, B. 2003. Estimating long-term average particulate air pollution concentrations: application of traffic indicators and geographic information systems. Epidemiol, 14: 228-239.

7. Cattle, J.A., McBratney, A.B. and Minasny, B. 2002. Kriging method evaluation for assessing the spatial distribution of urban soil lead contamination. J Environ Qual, 31: 1576-1588.

8. CDC 2003. Diesel particulate matter (as elemental carbon). Centers for Disease Control and Prevention.

9. Chan-Yeung, M., Khaled, N.A, White, N., Ip, M.S. and Tan, W.C. 2004. The burden and impact of COPD in Asia and Africa. Int J Tuberc Lung Dis, 8: 2-14.

10. Fonturbel, F.E., Barbieri, E., Herbas, C., Barbieri, F.L. and Gardon, J. 2011. Indoor metallic pollution related to mining activity in the bolivian altiplano. Environ Pollut, xxx: 1-6.

11. Gulliver, J., Hoogh, K.D., Fecht, D., Vienneau, D. and Briggs, D. 2011. Comparative assessment of GIS-based methods and metrics for estimating long-term exposure to air pollution. Atmospheric Environ, xxx: 1-9.

12. Global Initiative for Chronic Obstructive Lung Disease (GOLD). 2017-a. Global strategy for the diagnosis, management, and prevention of chronic obstructive pulmonary disease. GOLD website. http://goldcopd.org/download/326/. Published Jan- 
uary 2017. Accessed April 26, 2017.

13. Global Initiative for Chronic Obstructive Lung Disease (GOLD). 2017-b. Pocket guide to COPD diagnosis, management, and prevention; a guide for health care professionals. GOLD website. http:/goldcopd.org/wp-content/uploads/2016/12/ wms-GOLD-2017-Pocket-Guide.pdf. Published January 2017. Accessed April 26, 2017.

14. IARC. 2012. Diesel engine exhaust carcinogenic. Press release, 213.

15. IPCS. 1996. Diesel fuel and exhaust emissions. Environmental Health Criteria 171. International Programme on Chemical Safety.

16. Isaaks, E.H., Srivastava, R.M. 1989. An introduction to applied geostatistics. Oxford University Press, Toronto.

17. Matejicek, L. 2005. Spatial modelling of air pollution in urban areas with GIS: a case study on integrated database development. Adv Geosci, 4: 63-68.

18. MSHA. 2013. MSHA/OSHA hazard alert - diesel exhaust / diesel particulate matter. Mine Safety and Health Administration.

19. Parent, M., Rousseau, M., Boffeta, P., Cohen, A. and Siemiatycki J. 2007. Exposure to diesel and gasoline engine emissions and the risk of lung cancer. Am J Epidemiol, 165: 53-62.

20. Rushton, L. 2012. The problem with diesel: edito- rials. J Natl Cancer Inst, 104: 796-797.

21. Silverman, D.T., Samanic, C,M., Lubin, J.H., Blair, A.E., Stewart, P.A., Vermeulen, R., Coble, J.B., Rothman, N., Schleiff, P.L., Travis, W,D., Ziegler, R.G., Wacholder, S. and Attfield, M.D. 2012. The diesel exhaust in miners study: a nested case-control study of lung cancer and diesel exhaust. J Natl Cancer Inst, 104: 855-868.

22. Stinnette, J.D. and Souza, E.D. 2013. Establishing total airflow requirements for underground metal/ non metal mines with tier IV diesel equipment. 23rd World Mining Congress and Expo.

23. Susanto, A., Purwanto, P., Sunoko, H.R. and Setiani, O. 2017. A kriging method for mapping underground mine air pollution. Adv Sci Lett. 23: 2329-2332.

24. Susanto, A., Purwanto, P., Sunoko, H.R. and Setiani, O. 2016. Diesel engine exhaust emissions survey of underground mine in Indonesia. J Ind Pollut Contr. 32: 608-616.

25. USEPA. 2002. Health assessment document for diesel engine exhaust. National Center for Environmental Assessment: US Environmental Protection Agency.

26. Zou, B., Wilson, J.G., Zhan, F.B. and Zeng Y. 2009. Air pollutant exposure assessment methods utilized in epidemiological studies. J Environ Monit, 11: 475-490. 